\title{
Embedment of Chlorpheniramine Maleate in Directly Compressed Matrix Tablets of Compritol and Kollidone SR
}

\author{
Ehab A Fouad ${ }^{1,2}$, Mohamed A lbrahim ${ }^{2,4 *}$ and Mahmoud El-Badry ${ }^{2,3}$ \\ ${ }^{1}$ Department of Pharmaceutics, Almaarefa College for Science and Technology, P.O Box 71666, Riyadh 11597, Saudi Arabia; \\ ${ }^{2}$ Department of Pharmaceutics, Faculty of Pharmacy, Assiut University 71526, Assiut, Egypt; ${ }^{3}$ Department of Pharmaceutics, \\ College of Pharmacy, King Saud University. P.O. Box 2457, Riyadh 11451, Saudi Arabia; ${ }^{4}$ Department of Pharmaceutics and \\ industrial Pharmacy, Faculty of Pharmacy, Al-Azhar University, Assiut, Egypt.
}

*For correspondence: Email: abbma71@gmail.com; Tel: +966 114670681

\begin{abstract}
Purpose: To study the effect of compritol ATO888 and kollidon SR blend on the release of chlorpheniramine maleate (CPM) from its matrix tablets prepared by direct compression.

Methods: Different ratios of compritol and kollidon SR (containing $50 \%$ matrix component) in 1:1, 1:2, 1:3 and 3:1 ratios were formulated using direct compression. The formulations were organoleptically tested and investigated for CPM release.

Results: The release kinetics showed Fickian diffusion mode for kollidone and anomalous release mechanism for compritol matrices. Combining compritol as a lipophilic material and kollidone produced a matrix with controlled drug release. Retardation of drug release rate depended on the ratio of compritol to kollidon. The lower the compritol component, the slower the drug release rate. CPM in matrix tablets containing compritol:kollidone SR in a ratio of 1: 3 achieved optimized sustained release, where $44 \%$ of the drug was released within 8 h (versus $94.5 \%$ for compritol and $54.2 \%$ for kollidon matrix systems). The kinetics of drug release followed Fickian diffusion at low compritol concentration in the blend, reflecting the importance of pore formation. However, when compritol proportion was increased, drug release followed non-Fickian anomalous kinetics due to the water-repelling effect of compritol.

Conclusion: Compritol content of CPM matrix tablets can be used to modulate drug release rate as well as release kinetics.
\end{abstract}

Keywords: Chlorpheniramine maleate, Matrix tablets, Compritol, Kollidon, Drug release, Release kinetics

Tropical Journal of Pharmaceutical Research is indexed by Science Citation Index (SciSearch), Scopus, International Pharmaceutical Abstract, Chemical Abstracts, Embase, Index Copernicus, EBSCO, African Index Medicus, JournalSeek, Journal Citation Reports/Science Edition, Directory of Open Access Journals (DOAJ), African Journal Online, Bioline International, Open-J-Gate and Pharmacy Abstracts

\section{INTRODUCTION}

Sustained release oral dosage forms play important roles in the pharmaceutical industry [1]. Retarding drug release helps to improve patient compliance, minimize blood level fluctuation, reduces the amount of drug administered and consequently reduces systemic side effects [2]. Many pharmaceutical agents or materials are used to sustain or modify drug release such as the use of polymers for coating dosage forms, embedding drugs in hydrophilic or lipophilic matrices, or the use of controlled release tablets prepared as osmotic pump system [3].

Hydrophobic lipid based materials have been widely used for preparing tablet matrix for controlling drug release [4]. The lipid materials used for sustained release purpose especially for water soluble drugs, include compritol 888ATO 
(glyceryl behenate) [5], Glyceryl monostearate [6], and cetostearyl alcohol [7]. They are used for their compressibility and ability to hold drugs.

Compritol 888ATO (compritol) has been used for coating of oral sustained-release dosage forms [8]. As the amount of compritol in hot melt coating increases, prolongation of drug release takes place. The HLB value of compritol is 2 with a melting point of $71.3{ }^{\circ} \mathrm{C}$ [9]. Kollidon $\mathrm{SR}$ is composed of $80 \%$ polyvinyl acetate which is a plastic material that gives a coherent matrix upon compression, and $19 \%$ polyvinylpyrrolidone (PVP) which is a soluble pore forming material [10].

Chlorpheniramine maleate (CPM) has been used extensively as an antihistaminic drug for symptomatic relief of common cold and allergy. CPM is typically administered as $4 \mathrm{mg}$ dose, 2 to 3 times daily. It was selected in this study as a model drug for the highly water soluble compounds. The absolute bioavailability of CPM is 25 to $50 \%$ [11].

The aim of the present study is to investigate the potential of using mixture of compritol and kollidon SR to form a directly compressed matrix tablet as well as the effect of this combination on the sustain release behavior of CPM as a water soluble drug.

\section{EXPERIMENTAL}

\section{Materials}

Chlorpheniramine maleate (CPM) was generously obtained from Egyptian Pharmaceutical International Company (EPICO), Egypt. Kollidone SR was purchased from Dow Chemical Company, Midland, Michigan, USA. Compritol ${ }^{\circledR} 888$ ATO (Glyceryl behenates) was purchased from Gattefossé, Saint Priest, France.

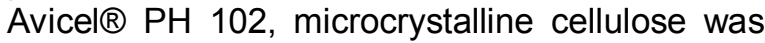
purchased from FMC BioPolymer, Ireland. Compactrol ${ }^{\circ}$ (calcium sulfate dihydrate) was kindly supplied by JRS Pharma, Germany. Magnesium stearate and hydrochloric acid were obtained from Riedel-de-Haen AG, Germany. All other chemicals were of analytical grade.

\section{Preparation of CPM matrix tablets}

Matrix tablets were prepared by direct compression. The matrix (F2 to F7) weighing 150 mg contained $10 \% \mathrm{w} / \mathrm{w}$ CPM, $19.5 \% \mathrm{w} / \mathrm{w}$ from each of compactrol and avicel PH102, $1 \% \mathrm{w} / \mathrm{w}$ magnesium stearate and $50 \% \mathrm{w} / \mathrm{w}$ of different ratios of compritol and kollidon SR. F1 is a control tablets containing $10 \%$ w/w CPM, $44.5 \%$ w/w from each of compactrol and avicel $\mathrm{PH} 102$ and $1 \% \mathrm{w} / \mathrm{w}$ magnesium stearate. Components of each matrix formulation were mixed in turbula mixer (type S27, Erweka, Apparatebau, Germany) for 15 min. Finally, the powder was compressed into tablets by an instrumented multiple press rotary tablet machine (Rotab T, kg pharma, Berlin, Germany) using $7 \mathrm{~mm}$ diameter, round, flat, and scored punches. Tablets hardness was kept within the range of $4-6 \mathrm{kp}$.

\section{Evaluation of physical properties of tablets}

Ten measurements of tablet hardness were conducted using hardness tester (type TBH28, Erweka, Apparatebau, Germany). The friability of 20 tablets was measured using Roche friabilator (type TA3R, Erweka, Apparatebau, Germany). Weight uniformity test of 20 tablets was carried out according to USP requirements.

\section{In vitro release studies}

The release of CPM from the prepared matrices was carried out in phosphate buffer $\mathrm{pH} 6.8$ using the USP apparatus II (Caleva Ltd., Model 85T). In brief, $900 \mathrm{ml}$ of the buffer was equilibrated to $37 \pm 0.5{ }^{\circ} \mathrm{C}$ at $50 \mathrm{rpm}$ attached to an IBM computer PK8620 series with PU 8605/60 dissolution test software where samples were withdrawn automatically with Watson-Marlow peristaltic pump lined to Philips VIS/UV/NIR single beam eight cell spectrophotometer Model PU 8620.

An accurately weighed CPM tablet of each of the prepared formulations was added to each vessel. Samples were withdrawn at pre-determined time intervals for $6 \mathrm{~h}$. The dissolution experiments were performed in triplicate for each batch and absorbance recorded automatically at $265 \mathrm{~nm}$. The cumulative percentage of drug released was determined as a function of time.

\section{Release kinetic analysis}

The released CPM was fitted as the fraction of total amount of drug released $\left(M_{t} / M_{\infty}\right)$ versus time $(\mathrm{t})$ according to different model equations. The model with best fitting was used to represent the mechanism of drug release. The following models were tested.

\section{Zero order}

$\mathrm{M}_{\mathrm{t}} / \mathrm{M}_{\infty}=\mathrm{k}_{0} \mathrm{t}$

where $\mathrm{k}_{0}$ is the zero order rate constant 


\section{First order}

$M_{t} / M_{\infty}=1-\exp ^{(-k 1 t)}$

where $\mathrm{k} 1$ is the first order rate constant

Higuchi diffusion model

$M_{t} / M_{\infty}=k_{h} t^{1 / 2}$

where $k_{h}$, is the Higuchi diffusion rate constant

Peppas and Korsemeyer model

$M_{t} / M_{\infty}=k_{p} t^{n}$

where $k_{p}$ is the release rate constant at the elapsed time $t, n$ is a constant. The value of $n \leq$ 0.45 indicates Fickian diffusion, $0.45 \leq \mathrm{n} \leq 0.89$ indicates non-Fickian (anomalous) diffusion, $\mathrm{n}=$ 0.89 indicates case-Il transport (erosion control and zero-order kinetics), and $n \geq 0.89$ indicates Super Case II transport [12].

All equations were fitted using the MULTI computer program with little modifications. The criteria for judging the best fitting included the examination of the predicted curve fitted to the data, and the sum of the squared residuals (SSR), as well as comparison of the Akaike's information criterion (AIC) [13]. AIC and SSR were calculated using Eqs 5 and 6, respectively.

$A I C=n\{\ln (S S R)\}+2 p$

$\mathrm{SSR}=\Sigma \Sigma \mathrm{W}_{\mathrm{ij}}\left\{\mathrm{C}_{\mathrm{i}, \mathrm{j}}-f\left(\mathrm{t}_{\mathrm{j}}, \mathrm{P}\right)\right\}^{2}$

where $\mathrm{n}$ is the number of experimental points, and $p$ is the number of parameters to be estimated.

\section{Tensile strength determination}

The radial tensile was computed using Eq 7 [14]:

$\sigma_{x}=2 \mathrm{~F} / \pi \mathrm{DT}$

where $\sigma_{x}$ is the tensile strength, $F$ is the force required to break the tablet, $D$ is the diameter of the tablet, and $\mathrm{T}$ is the tablet thickness.

\section{Statistical analysis}

Data analyses were performed using the Statistical Package for Social Sciences (SPSS ver. 19.0). Analysis of variance (ANOVA) was applied to determine statistical difference, which was considered significant at $p<0.05$.

\section{RESULTS}

Table 1 illustrates the amounts of compritol and kollidon present in the tested matrices and their organoleptic properties. Comparing the mean weight of F2 (50\% compritol) and F3 (50\% kollidone) showed almost the same weight and reflected a comparable density between compritol and kollidon. The hardness of matrix containing compritol only was significantly ( $p<$ 0.05 ) higher than kollidone rich formula, also, the same effect was observed in case of thickness. Upon mixing compritol with kollidon in varying ratios, the matrices' properties were affected in an irregular manner. However, the mode of change in such properties (thickness and hardness) with increasing compritol content appeared proportional.

Table 1: Composition and physical properties of CPM extended release matrix tablets (Mean \pm SD)

\begin{tabular}{|c|c|c|c|c|c|c|c|}
\hline \multirow{2}{*}{ Variable } & \multicolumn{7}{|c|}{ Formulation } \\
\hline & $F 1$ & $F 2$ & F3 & $F 4$ & $F 5$ & F6 & F7 \\
\hline $\begin{array}{l}\text { Compritol } \\
\text { ATO888 (mg\%) }\end{array}$ & - & 50 & - & 25 & 12.5 & 37.5 & 16.7 \\
\hline $\begin{array}{l}\text { Kollidone® SR } \\
(\mathrm{mg} \%)\end{array}$ & - & - & 50 & 25 & 37.5 & 12.5 & 33.3 \\
\hline Compactrol & 44.5 & 19.5 & 19.5 & 19.5 & 19.5 & 19.5 & 19.5 \\
\hline $\begin{array}{l}\text { Magnesium } \\
\text { stearate }\end{array}$ & 1 & 1 & 1 & 1 & 1 & 1 & 1 \\
\hline Avicel $^{(B)}$ & & & & $100 \%$ & & & \\
\hline $\begin{array}{l}\text { Weight } \\
\text { (mg) }\end{array}$ & $\begin{array}{l}151.5 \\
\pm 2.17\end{array}$ & $\begin{array}{l}143.1 \\
\pm 1.10\end{array}$ & $\begin{array}{r}143.0 \\
\pm 1.05\end{array}$ & $\begin{array}{r}147.8 \\
\pm 1.75\end{array}$ & $\begin{array}{l}146.4 \\
\pm 1.17\end{array}$ & $\begin{array}{r}140.4 \\
\pm 1.65\end{array}$ & $\begin{array}{r}142.2 \\
\pm 1.03\end{array}$ \\
\hline Thickness (mm) & $\begin{array}{c}2.71 \\
\pm 0.01\end{array}$ & $\begin{array}{l}3.17 \\
\pm 0.03\end{array}$ & $\begin{array}{c}2.98 \\
\pm 0.03\end{array}$ & $\begin{array}{c}3.13 \\
\pm 0.02\end{array}$ & $\begin{array}{c}3.11 \\
\pm 0.03\end{array}$ & $\begin{array}{l}3.05 \\
\pm 0.04\end{array}$ & $\begin{array}{r}2.97 \\
\pm 0.06\end{array}$ \\
\hline $\begin{array}{l}\text { Hardness } \\
\text { (Kp) } \\
\text { Friability (\%) }\end{array}$ & $\begin{array}{c}4.24 \\
\pm 0.50 \\
0.40\end{array}$ & $\begin{array}{c}5.51 \\
\pm 0.28 \\
0.35\end{array}$ & $\begin{array}{r}3.15 \\
\pm 0.26\end{array}$ & $\begin{array}{c}5.04 \\
\pm 0.49\end{array}$ & $\begin{array}{l}5.02 \\
\pm 0.31\end{array}$ & $\begin{array}{c}4.61 \\
\pm 0.15\end{array}$ & $\begin{array}{r}4.83 \\
\pm 0.35\end{array}$ \\
\hline
\end{tabular}


F1 thickness was $2.71 \mathrm{~mm}$ (control tablet without Kollidon SR or Compritol), which was recorded as the lowest thickness of the tablets

\section{In vitro release profiles}

Figure 1 presents the release profile of CPM release from the prepared matrices.

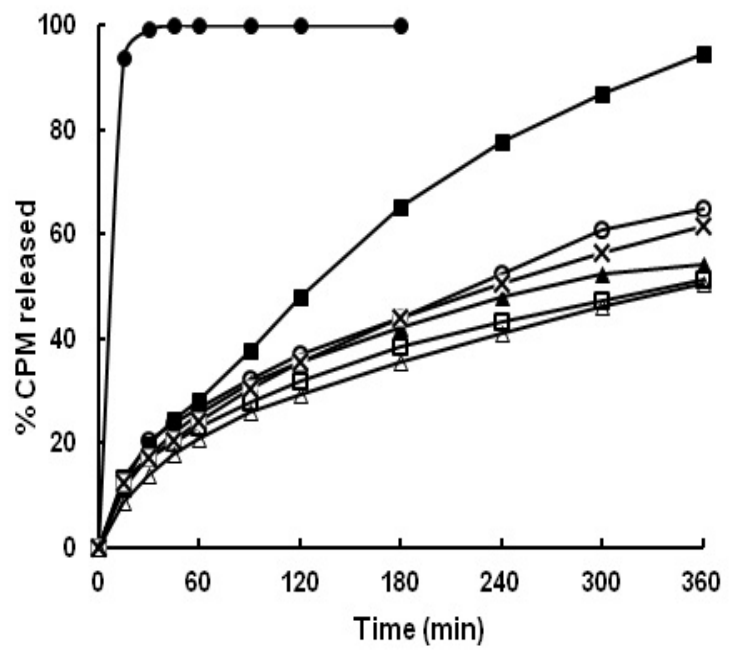

Fig. 1: Release profile of CPM from the prepared matrices $($ Key: • = F1, $\bullet=F 2, \boldsymbol{\Delta}=\mathrm{F} 3,=\mathrm{F} 4, \square=\mathrm{F} 5$, $\mathrm{x}=\mathrm{F} 6, \Delta=\mathrm{F} 7)$

It is apparent that kollidon alone in matrix slowed the release of CPM when compared to compritol alone. However, mixing kollidon with compritol in different ratios slowed the release rate more than that of compritol alone or when compritol composes $25 \% \mathrm{w} / \mathrm{w}$ (f4) or $37.5 \%$ (F6). It will also found to be slower than that of kollidon alone when used in $12.5 \%$ (F5) and $16.5 \%$ (F7) compritol. On the other hand, as the ratio of 25 to $33 \%$ of compritol in the matrix mixture decreased, the release increased in an extent higher than that was observed with kollidone alone. Although the ranking of the release rate could be $\mathrm{F} 7<\mathrm{F} 5<\mathrm{F} 6<\mathrm{F} 4$; Where the percent release were 50.34, 51.11, 61.61 and $64.94 \%$, respectively, there was insignificant difference between F4 compared to F6 and F5 compared to F7.

\section{Release kinetics}

Table 2 represents the fitting parameters of CPM release according to different models. Taking compritol-kollidone mixture as $100 \%$, the data showed best fitting for non-fickian anamolous diffusion kinetics as the weight of compritol in the matrix increased.

\section{Tensile strength}

Fig 2 represents the difference between the tensile strength of the prepared matrices and the expected tensile strength. It was found that the presence of compritol increases the tensile strength of the matrix.

Table 2: Release kinetic parameters derived from various models

\begin{tabular}{ccccccc}
\hline \multirow{2}{*}{$\begin{array}{c}\text { Formu- } \\
\text { lation }\end{array}$} & \multicolumn{3}{c}{ Zero order } & & & \\
& & & & & First order & \\
\cline { 2 - 7 } & $\mathbf{k}_{\mathbf{0}}$ & SSR & AIC & $\mathbf{k}_{1}$ & SSR & AIC \\
\hline F2 & 0.00305 & 0.1029 & -20.741 & 0.00607 & 0.0114 & -42.764 \\
F6 & 0.00204 & 0.0959 & -21.44 & 0.00317 & 0.0345 & -31.682 \\
F4 & 0.00215 & 0.1164 & -19.508 & 0.00346 & 0.0438 & -29.281 \\
F7 & 0.00167 & 0.0689 & -24.741 & 0.00236 & 0.0339 & -31.829 \\
F5 & 0.00175 & 0.1043 & -20.6 & 0.00254 & 0.0562 & -26.791 \\
F3 & 0.00191 & 0.1252 & -18.779 & 0.00292 & 0.0584 & -26.399 \\
\hline
\end{tabular}

\begin{tabular}{|c|c|c|c|c|c|c|c|}
\hline \multirow{2}{*}{$\begin{array}{l}\text { Formu- } \\
\text { lation }\end{array}$} & \multicolumn{3}{|c|}{ Higuchi model } & \multicolumn{4}{|c|}{ Peppas and Korsemeyer model } \\
\hline & $k_{h}$ & SSR & AIC & MDT & $\mathbf{n}$ & SSR & AIC \\
\hline $\mathrm{F} 2$ & 0.04728 & 0.03198 & -32.426 & 146.97 & 0.647 & 0.003707 & -51.975 \\
\hline F6 & 0.03234 & 0.0003 & -78.976 & 310.66 & 0.516 & 0.000123 & -85.996 \\
\hline $\mathrm{F} 4$ & 0.03416 & 0.00118 & -65.383 & 288.14 & 0.497 & 0.001179 & -63.432 \\
\hline $\mathrm{F} 7$ & 0.02657 & 0.00035 & -77.579 & 462.87 & 0.507 & 0.000238 & -76.233 \\
\hline F5 & 0.02809 & 0.00216 & -59.386 & 502.29 & 0.439 & 8.26E-05 & -90.013 \\
\hline F3 & 0.03065 & 0.00327 & -55.216 & 402.37 & 0.448 & 0.001446 & -61.387 \\
\hline
\end{tabular}

${ }^{*}$ Percent ratio of compritol with Kollidone SR; $¥, 100 \%$ Kollidone SR; $k(s)$, represent the rate constant of the model; N. B. Compritol and Kollidone SR represent $50 \%$ of tablet weight 


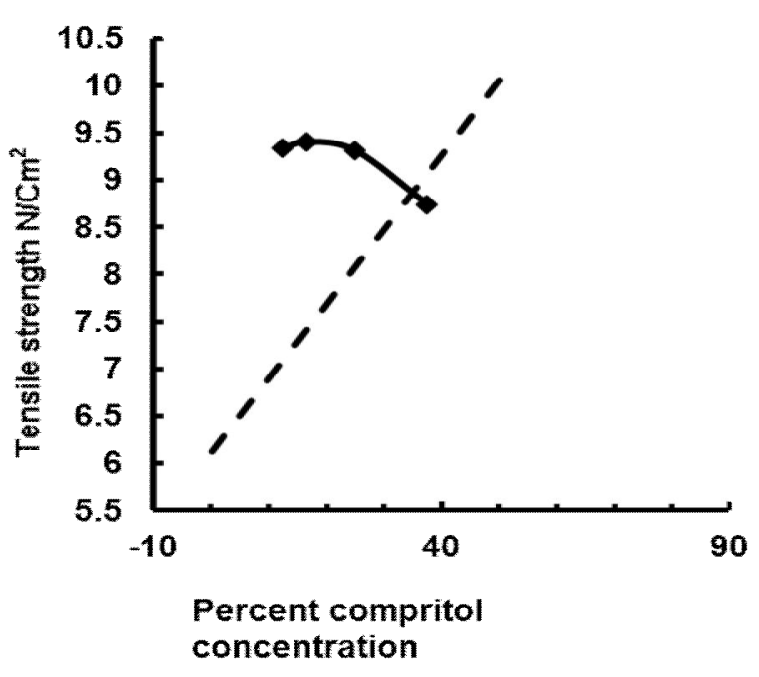

Fig 2: Effect of compritol on the tensile strength of the matrix tablets (Key: = tensile strength, dotted line = expected tensile strength).

\section{Drug release response}

The release response was determined by calculating the area under the curve for the release profile, while the response ratio was determined by dividing the release response of a specified matrix by that of matrix containing kollidone only.

Studying the release behavior of drug through different matrices composition was conducted using the release response. Fig 3 shows the ratio of release response from different matrices to that of kollidon alone. The results revealed one phase for $\mathrm{F} 5$ and more than one phase of response for F4, F6 and F7.

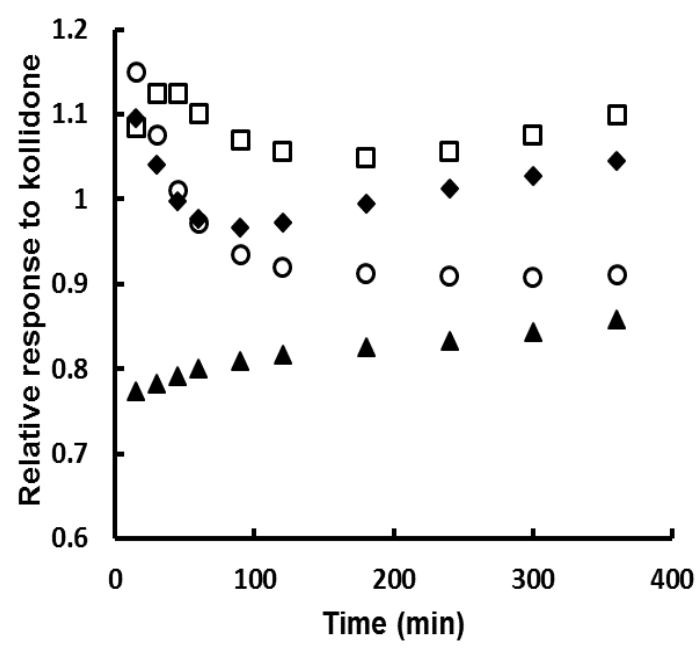

Fig. 3: Relative response ratio of CPM release from matrix containing different ratios of Kollidone SR and compritol to that of kollidon SR only. (Key: $\square=F 4,=$ F5, = F6, $\boldsymbol{\Delta}$ = F7)

\section{DISCUSSION}

The increased thickness of matrices other than $\mathrm{F} 1$ reflects a difference in compressibility and/or polymer relaxation either for compritol or kollidon $\mathrm{SR}$. On the other hand, addition of compritol to kollidon resulted in increased hardness of matrices, which improved the resistance of matrices toward vibration or friability. In regard to the tested properties, it is obvious that all the prepared formulations showed satisfactory hardness and friability.

Incorporation of compritol with kollidon in ( $\mathrm{F} 4$ and F6) increased the drug release when compared to F3, F5 and F7. This may be attributed to the increased amount of kollidon incorporated on the expense of compritol, where kollidon reached $100 \%$ of the matrix composition in case of $\mathrm{F} 3$. According to penetration theory, when a matrix is composed of a water-soluble drug and a waterinsoluble polymer, drug release occurs mainly by dissolution of the active ingredient through capillaries composed of interconnecting drug particle clusters and the pore network [15]. As drug release continues, the interconnecting clusters increase the pore network through which interior drug clusters can diffuse with more compritol particles present, then fewer clusters of soluble drug are formed. In this case, a finite drug cluster should remain which appear statistically plausible.

This result may recommend that the large hydrophobic molecules of compritol impose a discontinuity in the kollidon matrix structure leading to formation of a weaker arrangement, which at lower concentration, affects the tortuous formation than in matrix containing kollidon alone [16].

Tablets must have a minimum mechanical strength to withstand the potential loading encountered during processing and handling. It has been shown that the tensile strength of tablets of a particulate powder is primarily a function of its porosity or relative density, irrespective of the dimensions of the tablets [17]. When compritol was used as a lubricant for its hydrophobic nature, compritol decreased the tensile strength of tablet and slowed drug release [18]. This effect appears in concentration up to 3 $\%$, however, in the present study compritol has been used in a concentration starting from 12.5 up to $50 \%$ of total tablet weight.

As seen in Figure 2, the tensile strength for matrix containing blend of kollidon and compritol is higher than expected which means an increase in the interparticle bonding that reached 
its maximum value when $16.5 \%$ compritol was used. Also, it reflected an increase in the adhesive forces over the cohesive forces for the particles of each material alone.

Increasing percent Kollidon SR in matrix containing microcrystalline cellulose resulted in higher mechanical strength, especially in case of F6, where the lowest amount of Kollidon was used, $p \square 0.05$ (12.5\% of the matrix), that appears in agreement with lovanov et al [19]. The release from the present matrix depend on pore forming materials which are CPM, a soluble drug that is constant in all matrices, and PVP that increases with increasing kollidon percent. Also pores may be formed during compression. It is probable that after compression, compritol tightly bound with kollidon SR. The increased rate of release in the presence of $50 \%$ or more compritol may be attributed to the water repelling property of compritol.

Slowing drug release rate depended on the ratio of compritol to kollidon. The lower the compritol ratio, the slower is drug release rate. The kinetics of drug release followed fickian diffusion in low compritol concentration reflecting the importance of pore formation. However, by increasing compritol concentration, drug release followed non fickian anomalous kinetics due to the repelling effect of compritol.

The results in Fig 3 confirmed the presence of more than one mechanism of release for F4, F6 and F7. However, F3 and F5 showed almost fickian release kinetics. These results strengthen the data obtained through korsmeyer peppas fitting, where $0.45<n<0.89$ [12].

Taking into consideration that all the tested matrices did not disintegrate during release. The burst effect may be attributed to the amount of drug present on the surface and the relatively higher porosity that caused easy penetration of dissolution medium as well as the repelling effect of compritol. Generally, as the proportion of kollidone increased, the effect of pores on drug release also increased showing fickian diffusion mechanism, F3 and F5. However, as compritol increased above $12.5 \%$, the repelling effect mechanism became detectable. As percent compritol increased up to $50 \%$, the holding ability and binding capacity to kollidon also increased. In this case, mean dissolution time (MDT) decreased with the predomination of repelling effect. This effect is in agreement with previous report [20], where the effect of different waxes on the release of diltiazem hydrochloride from kollidon matrices was studied.

\section{CONCLUSION}

Controlling drug release matrix prepared by direct compression is usually a huge challenge. Combining Compritol as a lipophilic material and Kollidon as a plastic forming material produces a matrix suitable for controlled release of chlorpheniramine. Adjusting drug release rate can be achieved by adjusting Compritol/Kollidon ratio.

\section{ACKNOWLEDGEMENT}

The authors extend their appreciation to the Deanship of Scientific Research at KSU for funding the work through the Research Group Project no. RGP-299.

\section{REFERENCES}

1. Jover Cl, Garcia ME, Minarro CM, Perez LP, Orriols RE, Sune NJM, Tico GJR. Modified release oral dosage forms. Cienciay Tecnol Pharm 2003; 13: 129-135.

2. McCarberg B. Tramadol extended-release in the management of chronic pain. Ther. Clin. Risk Manage 2007; 3: 401-441.

3. Chansanroj $K$, Betz B. Sucrose esters with various hydrophilic-lipophilic properties: novel controlled release agents for oral drug delivery matrix tablets prepared by direct compaction. Acta Biomater 2010; 6: 3101-3109.

4. Miyagawa $Y$, Okabe $T$, Yamaguchi $Y$, Miyajima M, Sato $H$, Sunada $H$. Controlled-release of diclofenac sodium from wax matrix granules. Int J Pharm 1996; 138: 215-224.

5. Hariharan M, Wowchuk C, Nkansah P, Gupta VK. Effect of formulation composition on the properties of controlled release tablets prepared by roller compaction. Drug Dev Ind Pharm 2004; 30: 565-572.

6. Bhagwat DA, Kawtikwar PS, Sakarkar DM. Sustained Release Matrices of Verapamil HCl Using Glyceryl Monosterate and Stearic Acid, Res J Pharm Tech 2008; 1: 405-409.

7. Quadir MA, Rahman MS, Karim MZ, Akter S, Awkat MT, Reza MS. Evaluation of hydrophobic materials as matrices for controlled-release drug delivery. Pak $J$ Pharm Sci 2003; 16: 17-28.

8. Faham A, Prinderre $P$, Farah N, Eichler KD, Kalantzis $G$, Joachim J. Hot-melt coating technology. I. Influence of Compritol 888 ATO and granule size on theophylline release, Drug Dev Ind Pharm 2000; 26: 167-176.

9. Fouad EA, EL-Badry M, Mahrous GM, Alsarra IA, Alashban Z, Alanazi FK. In vitro investigation for embedding dextromethorphan in lipids using spray drying. Digest J Nanomat Biostruc 2011; 6: 11291139. 
10. BASF Aktiengesellschaft, Technical Information, kollidone SR, 2011.

11. Rumore MM. Clinical pharmacokinetics of chlorpheniramine. Drug Intell Clin Pharmacy 1984; 18: 701-707.

12. Ritger PL, Peppas NA. A simple equation for description of solute release. II. Fickian and anomalous release from swellable devices. J Control Release 1987; 5: 37-42.

13. Yamaoka K, Nakagawa T, Uno T. Application of Akaike's information criterion (AIC) in the evaluation of linear pharmacokinetic equations. I Pharmacokinet Biopharm 1978; 6: 165-175.

14. Fell JT, Newton JM. Determination of tablet strength by the diametrical compression test. J Pharm Sci 1970; 59: 688-691.

15. Holman JE, Leuenberger $H$. The relationship between solid fraction and mechanical properties of compacts - the Percolation Theory model Approach. Int J Pharm 1988; 46: 35-44.
16. Khan MA, Maheshwari RK. Studies of relationship between swelling and drug release in the sustained release hydrophilic matrices containing different grades of hydroxypropyl methylcellulose. RJPBCS 2011; 2: 970-975.

17. Wu C, Best SM, Bentham AC, Hancock BC, Bonfield WA. A simple predictive model for the tensile strength of binary tablets. Eur J Pharm Sci 2005; 25: 331-336.

18. Jarosz PJ, Parrott EL. Effect of lubricant on tensile strengths of tablets. Drug Dev Ind Pharm 1984; 10 : 2059-2073.

19. Iovanov RII, Tomuta I, Leucuta SE. The optimization of prolonged release of matrix tablets with felodipine. Farmacia 2008; 56: 290-299.

20. Islam MS, Reza S, Rahman H. In vitro Release Kinetics Study of Diltiazem Hydrochloride from Wax and Kollidon SR Based Matrix Tablets. Iran J Pharma Res 2008; 7: 101-108. 